\title{
Long-term and Perioperative Outcomes of Laparoscopic and Open Surgery for Rectal Cancer
}

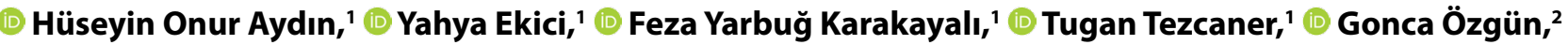 \\ Sedat Yıldırım, ${ }^{1}$ (D) Gökhan Moray ${ }^{1}$ \\ 'Department of General Surgery, Baskent University Faculty of Medicine, Ankara, Turkey \\ ${ }^{2}$ Department of Pathology, Baskent University Faculty of Medicine, Ankara, Turkey
}

\begin{abstract}
Objectives: The necessity of comparing oncologic results with the use of minimally invasive surgery in rectal cancer has arisen. The aim of the present study was to evaluate the treatment approach in rectal cancer and to compare the outcomes of laparoscopic and open surgery.

Methods: Patients who underwent surgery for rectal carcinoma between January 2006 and January 2016 in our institution were evaluated. The results were compared between the two groups according to open or laparoscopic surgery. Clinical characteristics, preoperative and postoperative results, pathological examination results, and disease-free survival rates were compared after the surgical procedure.

Results: A total of 121 patients were included in the study. Of the patients, 50 underwent open, and 71 underwent laparoscopic surgery. The median follow-up times were 56.75 months in the open surgery group and 55.2 months in the laparoscopic surgery group. Pathological examination revealed similar numbers of lymph nodes in both groups ( $p>0.05$ ). The duration of hospital stay was statistically significantly lower in the open surgery group than in the laparoscopic group $(p<0.05)$. The rates of disease-free survival were $74 \%$ in the open surgery group and $82.5 \%$ in the laparoscopic group, and no statistically significant difference was found ( $p>0.05)$.

Conclusion: There was no significant difference in complication and recurrence between laparoscopic and open surgery for rectal cancer in our study. The duration of hospital stay of patients was statistically significantly lower in the laparoscopic group than in the open surgery group. Laparoscopic or open surgical options could be preferred according to the clinical suitability of the patient, experience of the surgeon, and resources of the center in rectal cancer treatment.

Keywords: Disease-free survival; laparoscopic surgery; open surgery; rectum cancer.

Please cite this article as "Aydın HO, Ekici Y, Yarbuğ Karakayalı F, Tezcaner T, Özgün G, Yıldırım S, Moray G. Long-term and Perioperative Outcomes of Laparoscopic and Open Surgery for Rectal Cancer. Med Bull Sisli Etfal Hosp 2018;52(4):285-288".
\end{abstract}

C olorectal cancers are common worldwide. According to the 2014 Turkish Statistical Institute, it is the fourth most common cancer type in Turkey. The biological structure of colorectal cancers may vary according to their location in the colon. ${ }^{[1]}$ It is recommended that colorectal cancers be examined into two separate groups, as rectum tumors metastasize to the lymph nodes more frequently than colon tumors, and complications, such as anastomosis leakage after rectal surgery, are more frequent. ${ }^{[2,3]}$

The treatment of rectum cancers has always been challenging. With the use of laparoscopic surgery, the necessity of comparing open surgery with oncologic results arises. In

Address for correspondence: Hüseyin Onur Aydın, MD. Başkent Üniversitesi Tıp Fakültesi, Genel Cerrahi Anabilim Dalı, Ankara, Turkey Phone: +90 3122030520 E-mail: dronuraydin@hotmail.com

Submitted Date: November 30, 2017 Accepted Date: December 01, 2017 Available Online Date: December 28, 2018

${ }^{\circ}$ Copyright 2018 by The Medical Bulletin of Sisli Etfal Hospital - Available online at www.sislietfaltip.org

This is an open access article under the CC BY-NC-ND license (http://creativecommons.org/licenses/by-nc/4.0/). 
recent years, some studies report that laparoscopic surgery for colon carcinoma is associated with earlier postoperative recovery, lower morbidity, and equivalent long-term outcomes. $^{[4,5]}$ However, these benefits of laparoscopic surgery for rectum cancer were still controversial. Some studies indicate that there is no significant difference in oncologic outcomes between laparoscopic and open surgery in rectal cancer in the meta-analyses performed. ${ }^{[6]}$ However, more research is needed in the literature to compare the oncologic outcomes of both techniques.

The aim of the present study was to evaluate the outcomes of patients who underwent laparoscopic and open surgery for rectal cancer in terms of perioperative outcomes and disease-free survival.

\section{Methods}

The study was approved by the Baskent University Institutional Review Board (project no. KA17/292) and supported by the Baskent University Research Fund. All consecutive patients who underwent surgery for rectal carcinoma in our hospital between January 2006 and January 2016 were evaluated retrospectively. Patients who were $<18$ years old, who had no follow-up information, who had stage 4 disease, and who had emergency surgery for obstruction or perforation were excluded from the study. Age, gender, postoperative hemoglobin levels, and C-reactive protein (CRP) levels of patients who met the criteria were examined. The patients were divided into two different groups according to surgical method whether laparoscopic or open. The preoperative computed tomography (CT) and magnetic resonance imaging (MRI) findings were evaluated in terms of locally advanced disease and postoperative anastomotic leakage, surgical complication, surgical margin for pathological evaluation, and number of lymph nodes removed. The duration of recurrence or metastases in the patients' follow-up and the disease-free survival rates of patients were investigated.

After endoscopic diagnosis of the disease, preoperative evaluation was made by CT and MRI scans, and the invasion grade of the rectum wall was determined. Neoadjuvant therapy was applied to the patient with metastatic lymph node in the perirectal fat mass and the tumor exceeding to the muscularis propria. Patients who underwent open or laparoscopic surgical resection were treated with low anterior and abdominoperineal resection with total mesorectal excision technique as previously described..$^{[7-9]}$

\section{Statistical Analysis}

Statistical analysis was performed using the SPSS version 21.0 program (IBM Corp., Armonk, NY, USA). Demographic and clinical characteristics were expressed in frequency or percentage for categorical data, in mean \pm standard deviation (SD) for continuous parametric variables, and in median (interquartile range) for continuous non-parametric variables. Differences between the groups were evaluated by the Pearson's chi-square test, two-sample t-test, Wilcoxon rank sum test, analysis of variance, or Kruskal-Wallis test, as appropriate. Student's test was used to compare two groups, and Kaplan-Meier test was used to assess disease-free survival. A $p$ value of $<0.05$ was considered statistically significant.

\section{Results}

A total of 121 patients, 84 of them were male, were included in the study. Fifty patients underwent open surgery, and 71 patients underwent laparoscopic surgery. The preoperative data of the patients are shown in Table 1 . There were no statistical differences between the groups in terms of age, gender, laboratory values, and stage ( $p>0.05)$. In the open surgery group, the mean number of lymph nodes removed during resection was $14.5(\mathrm{SD} \pm 6.6)$, and the mean number of metastatic lymph nodes was $2.36(\mathrm{SD} \pm 4.8)$. The mean length of hospital stay was 7.2 ( $\mathrm{SD} \pm 4.3$ ) days. In the laparoscopic surgery group, 45 male and 26 female patients were treated. The mean number of lymph nodes removed during resection was $14.55(\mathrm{SD} \pm 4.55)$, and the mean number of metastatic lymph nodes was 1.48 (SD \pm 3.76$)$. The mean duration of hospital stay was $5.8(\mathrm{SD} \pm 1.7)$ days. Pathological evaluation revealed similar numbers of lymph nodes in both groups ( $p>0.05$ ). The hospitalization period was statistically significantly lower in the open surgery group than in the laparoscopic group $(p<0.05)$. Postoperative results are shown in Table 2. The median follow-up periods were 56.75 months and 55.2 months in the open surgery group and laparoscopic surgery group, respectively. In the open surgery group, local recurrence was seen in $3(6 \%)$ patients and distant organ metastasis in $6(12 \%)$ patients, whereas in the laparoscopic surgery group, local recurrence was seen in 4 (5.6\%) patients and distant organ metastasis in 7 (9.9\%) patients during the follow-up period. The disease-free survival rates were $74 \%$

Table 1. Preoperative findings of the open and laparoscopic surgery groups

\begin{tabular}{lcc}
\hline & $\begin{array}{c}\text { Open } \\
\text { surgery }\end{array}$ & $\begin{array}{c}\text { Laparoscopic } \\
\text { surgery }\end{array}$ \\
\hline Gender (female/male) & $11 / 39$ & $26 / 45$ \\
Age, year (mean) & $67.34 \pm 12.16$ & $62.90 \pm 13.91$ \\
Hemoglobin, g/dL (mean) & $12.83 \pm 1.07$ & $12.64 \pm 1.11$ \\
C-reactive protein, mg/L (mean) & $15.48 \pm 32.99$ & $12.59 \pm 22.71$ \\
Locally advanced stage & $18(\% 36)$ & $24(\% 33.8)$ \\
Neoadjuvant chemotherapy & $2(\% 4)$ & $12(\% 16.9)$ \\
Neoadjuvant radiotherapy & $4(\% 8)$ & $19(\% 26.8)$ \\
\hline
\end{tabular}


Table 2. Postoperative findings of the open and laparoscopic surgery groups

\begin{tabular}{lcc}
\hline & $\begin{array}{c}\text { Open } \\
\text { surgery }\end{array}$ & $\begin{array}{c}\text { Laparoscopic } \\
\text { surgery }\end{array}$ \\
\hline Surgery type & & \\
$\quad$ Low ant. res. & 41 & 65 \\
$\quad$ APR & 9 & 6 \\
Blood transfusion & $3(\% 6)$ & $12(\% 16.9)$ \\
Metastatic/total lymph node (mean) & $2.36 / 14.50$ & $1.48 / 14.55$ \\
Surgical margin & Negative & Negative \\
Hospital stay, day & $7.2 \pm 4.3$ & $* 5.8 \pm 1.7$ \\
Complication & & \\
$\quad$ Surgical site infection & 10 & 5 \\
$\quad$ Anastomotic leakage & 1 & 5 \\
\hline * & &
\end{tabular}

${ }^{*} p<0.05$.

Table 3. Results during follow-up

\begin{tabular}{lcc}
\hline & $\begin{array}{c}\text { Open } \\
\text { surgery }\end{array}$ & $\begin{array}{c}\text { Laparoscopic } \\
\text { surgery }\end{array}$ \\
\hline Follow-up, month (median) & 56.75 & 55.20 \\
Local recurrence & $3(\% 6)$ & $4(\% 5.6)$ \\
Distant metastasis & $6(\% 12)$ & $7(\% 9.9)$ \\
Disease-free survival & $\% 74$ & $\% 82.5$ \\
\hline
\end{tabular}

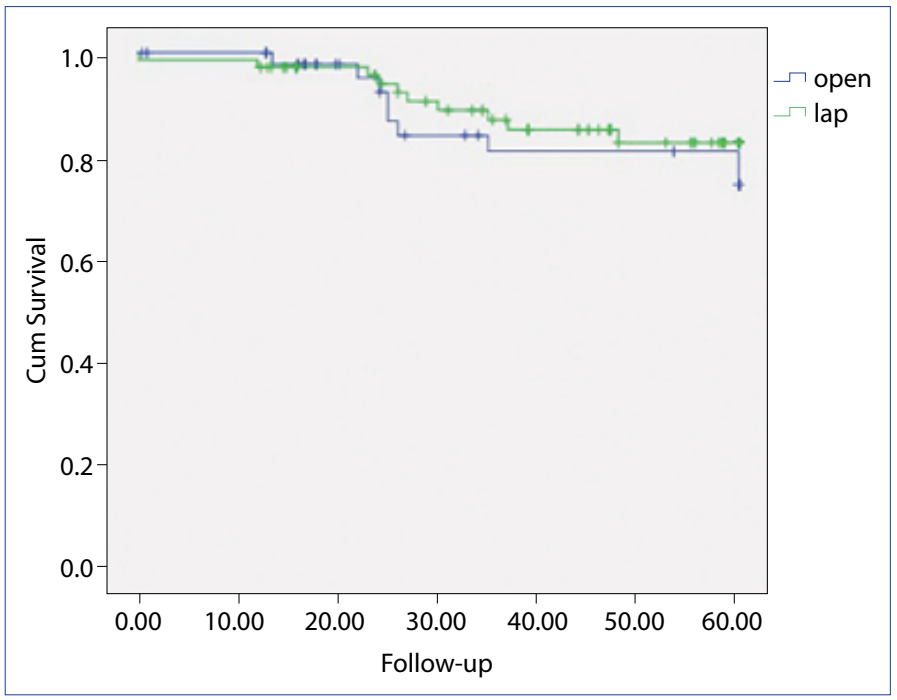

Figure 1. Kaplan-Meier survival analysis ( $p>0.05)$.

in the open surgery group and $82.5 \%$ in the laparoscopic group. No statistically significant difference was found between the two groups ( $p>0.05$ ) (Table 3) (Fig.1).

\section{Discussion}

In 1991, after the first laparoscopic colon resection was described by Jacobs et al. ${ }^{[10]}$, it is used as an alternative treat- ment option for colon cancer because of the short-term benefits and similar long-term outcomes when compared with the open surgery technique. ${ }^{[1]}$ Despite the improvements in this area, there is still a necessity to compare the laparoscopic and open surgery techniques in terms of oncologic outcomes in the treatment of rectal cancers.

In the present study, we aimed to compare the short-term complication, the length of hospitalization, the number of lymph nodes removed, and the duration of disease-free survival in the long-term for patients treated with laparoscopic or open surgical methods for rectal cancer. The number of lymph nodes removed in both patient groups was similar, and early complications seen in the first 30 days after surgery were similar. Although, it was observed that wound infection was more frequent in open surgery patients, but there was no statistically significant difference. It was observed that the length of hospital stay in patients who underwent laparoscopic surgery was statistically significantly low. There was no statistically significant difference between the long-term disease-free survival of the patients.

Human leukocyte antigen (HLA)-DR that is excreted from monocytes is a measure of immune competence. It is responsible for adequate antigen presentation and antigen-specific immunoreaction in humans. CRP is an indication of the activity of immunological reactions. Interleukin (IL)- 6 is used as postoperative complications and predictor of morbidity. Veenhof et al. ${ }^{[12]}$ reported that patients who underwent laparoscopic surgery are affected positively at HLA-DR, CRP, and IL-6 levels. Early recovery, early onset bowel motility, and short hospitalization may be associated with these effects in patients undergoing laparoscopic surgery.

It has been reported that there is no difference between wound infection, deep surgical infection, and anastomosis between laparoscopic and open surgery in the meta-analyses performed. The meta-analysis of 20 trials did not reveal any statistical difference between the two groups in terms of three parameters. ${ }^{[13]}$ Our study also concluded that patient groups had similar complication rates between laparoscopic and open surgery. Surgical technique and developments in used instruments are thought to help prevent potential complications.

A meta-analysis of 16 randomized controlled trials conducted by Zhang et al. ${ }^{[14]}$ showed that the short-term outcomes of patients undergoing laparoscopic surgery are less blood loss, onset of earlier bowel movements, and length of hospital stay. In a 5-year follow-up, no significant difference was found between patients who underwent laparoscopic and open surgery in terms of oncologic outcomes. 


\section{Conclusion}

The retrospective nature of our work is limited by the fact that patients' follow-up cannot be standardized. Another limitation is the heterogeneity of the patients in both groups and the limited number of patients in the groups. Despite these limitations, our results show that there is no significant difference between laparoscopic and open rectal surgery. Particularly when clinical and oncologic outcomes were compared and disease-free survival times were compared, it was seen that there was no difference between the two techniques. The length of stay at the hospital can be seen as a brief advantage of laparoscopic technique, but the long-term similarity of oncologic outcomes makes the two techniques almost equivalent. For this reason, more clinical trials are needed to determine in selecting laparoscopic or open surgical procedures.

\section{Disclosures}

Ethics Committee Approval: This study was approved by Baskent University Institutional Review Board (Project no: KA 17/292) and supported by Baskent University Research Fund.

Peer-review: Externally peer-reviewed.

Conflict of Interest: None declared.

Authorship Contributions: Concept - S.Y.; Design - Y.E.; Supervision - G.M.; Materials - G.Ö.; Data collection \&/or processing H.O.A., T.T.; Analysis and/or interpretation - Y.E.; Literature search - H.O.A.; Writing - H.O.A., Y.E.; Critical review - S.Y., G.M.

\section{References}

1. Frattini $M$, Balestra $D$, Suardi S, Oggionni M, Alberici P, Radice $P$, et al. Different genetic features associated with colon and rectalcarcinogenesis. Clin Cancer Res 2004;10:4015-21. [CrossRef]

2. Pommergaard HC, Gessler B, Burcharth J, Angenete E, Haglind E, Rosenberg J. Preoperative risk factors for anastomotic leakage after resectionfor colorectal cancer: a systematic review and meta-analysis. Colorectal Dis 2014;16:662-71. [CrossRef]

3. Wang $H$, Wei XZ, Fu CG, Zhao RH, Cao FA. Patterns of lymph node metastasis are different in colon and rectal carcinomas. World J Gastroenterol 2010;16:5375-9. [CrossRef]

4. Di B, Li Y, Wei K, Xiao X, Shi J, Zhang Y, et al. Laparoscopic versus open surgery for colon cancer: a meta-analysis of 5-year follow-up outcomes. Surg Oncol 2013;22:e39-43. [CrossRef]

5. Bonjer HJ, Hop WC, Nelson H, Sargent DJ, Lacy AM, Castells A, et al. Laparoscopically assisted vs open colectomy for colon cancer: a meta-analysis. Arch Surg 2007;142:298-303. [CrossRef]

6. Zhao D, Li Y, Wang S, Huang Z. Laparoscopic versus open surgery for rectal cancer: a meta-analysis of 3-year follow-up outcomes. Int J Colorectal Dis 2016;31:805-11. [CrossRef]

7. Heald RJ. The 'Holy Plane' of rectal surgery. J R Soc Med 1988;81:503-8. [CrossRef]

8. Kuroyanagi H, Oya M, Ueno M, Fujimoto $Y$, Yamaguchi T, Muto T. Standardized technique of laparoscopic intracorporeal rectaltransection and anastomosis for low anterior resection. Surg Endosc 2008;22:557-61. [CrossRef]

9. Miles WE. A method of performing abdomino-perineal excision for carcinoma of the rectum and of the terminal portion of the pelvic colon (1908). CA Cancer J Clin 1971;21:361-4. [CrossRef]

10. Jacobs M, Verdeja JC, Goldstein HS. Minimally invasive coIon resection (laparoscopic colectomy). Surg Laparosc Endosc 1991;1:144-50.

11. Theophilus $M$, Platell C, Spilsbury K. Long-term survival following laparoscopic and open colectomy for colon cancer: a meta-analysis of randomized controlled trials. Colorectal Dis 2014;16:075-81.

12. Veenhof $A A$, Vlug MS, van der Pas $M H$, Sietses $C$, van der Peet $D L$, de Lange-de Klerk ES, et al. Surgical stress response and postoperative immune function afterlaparoscopy or open surgery with fast track or standard perioperative care: a randomized trial. Ann Surg 2012;255:216-21. [CrossRef]

13. Aziz O, Constantinides V, Tekkis PP, Athanasiou T, Purkayastha S, Paraskeva $\mathrm{P}$, et al. Laparoscopic versus open surgery for rectal cancer: a meta-analysis. Ann Surg Oncol 2006;13:413-24. [CrossRef]

14. Zhang FW, Zhou ZY, Wang HL, Zhang JX, Di BS, Huang WH, et al. Laparoscopic versus open surgery for rectal cancer: a systematic review and meta-analysis of randomized controlled trials. Asian Pac J Cancer Prev 2014;15:9985-96. [CrossRef] 